\title{
Strategies of Cultivating Brand Loyalty in China
}

\author{
Wen Tingting \\ School of Marxism, \\ China West Normal University \\ Nanchong, China \\ 39706265@qq.com
}

\author{
Zhang Min \\ School of Foreign Languages, \\ China West Normal University \\ Nanchong, China \\ zhangmin62280@163.com
}

\begin{abstract}
Consumer brand loyalty is of great significance to enhance the competitiveness of China's domestic brands. From the four dimensions of brand loyalty: attitudinal loyalty, affective loyalty, conative loyalty and action loyalty, this paper does a comprehensive analysis of the consumer psychology of Chinese local brands and explore brand marketing strategy suitable for China's national conditions, expecting to be able to develop and improve the applicable management theory in the Chinese domestic brands.
\end{abstract}

Keywords- Brand Loyalty; Consumer; Countermeasure;

\section{INTRODUCTION}

Brand loyalty is particularly important for the development of enterprise in increasingly competitive society. Due to the perceived risk and information asymmetry, the dimensions of the consumer brand loyalty are influenced by multiple factors. The purpose of this article is to explore suitable brand loyalty management theory by recalling the researches home and abroad about brand loyalty, and analyzing some domestic famous brands' examples in enhancing brand loyalty.

\section{LITERATURE REVIEW OF THE THEORY OF BRAND LOYALTY}

\section{A. Foreign Literafure}

Since 1923 Copeland first proposed "brand continued brand loyalty", directly related to the concept of brand loyalty, there have been over 200 kinds of its definition (Jacoby and Chestnut, 1978). They generally from four angles define brand loyalty. The first angle is the consumer' actual purchasing behavior, that is, consumer behavior. For example, Tucker (1964) thinks that if consumers buy the same brand for 3 times, this behavior is brand loyalty; McConnell J.Douglas (1968) pointed out that continuing to purchase a certain brand for 3-5 times is brand loyalty. The second angle is the consumer' purchasing intent, that is, consumer attitudes. Jones (1995) pointed out that customer loyalty is a repeated purchasing intention for a specific product and service in the future. The third angle is a comprehensive view of consumer behavior and consumer attitudes. Biong (1993) pointed that loyalty manifested in consumers' accepting long-term corporate services and having a strong willingness to recommend to others, that is, the attitude loyalty and behavior loyalty constitute brand loyalty. The fourth angle is a comprehensive point of view based on consumer psychology and consumer behavior. Harris and Goode (2004) build brand loyalty from cognitive loyalty, affective loyalty, conative loyalty and behavioral loyalty.

\section{B. Domestic literature}

Qu Yunbo, who concerned about brand loyalty early (1996) pointed out that brand loyalty is a measure of consumer brand feelings; it reflects the possiblity for consumers to switch to another brand. JiJian andChen Xiaoping (1999) pointed that brand loyalty should include two aspects: behavioral loyalty and emotional loyalty. Luo Ziming (1999) pointed out that brand loyalty consists of 6 parts: the awareness, comprehensive evaluation of a brand, consumers' judgments, consumer satisfaction, the stability of consumers' spending habits, and consumers' introduction to other consumers. Though some empirical research LIU Li et al (2006) pointed out loyalty is divided into four parts: attitudinal loyalty, behavioral loyalty, positive cognitive and negative cognitive loyalty. It's clear that most domestic scholars analyze brand loyalty from emotional and behavioral loyalty. With the increasing competition and the increasing choices of goods, domestic scholars are very concerned about brand loyalty building, but still around behavioral loyalty and emotional loyalty, but research perspectives are diverse. Lu Juan (2003) from the angel of service industry' brand switching, explores how to cultivate customer loyalty in China's service industry; Zeng Ming Wang and Li Wei (2008) analyze the relationship between the degree of loss in the product damage events and risk, brand affect, brand trust, brand loyalty and brand awareness; the corporate sponsors motive Wan Chui Lin (2010) explores the relationship between sponsoring motives and brand loyalty though sports sponsors. Chinese enterprises sports sponsorship instance, consumer perception and brand loyalty relationship; Kong Lingming and GengXize (2012) define brand loyalty to B2B service brand, and discuss the effects of brand awareness and brand image on brand attitude loyalty and action loyalty. 


\section{THE BUILDING OF LOCAL BRANDS LOYALTY}

\section{A. the lack of local Chinese brand building}

Brand derives from the ancient Norwegian word "brandr", which means "burn". Brand is crucial for the survival and development of an enterprise. Many domestic brands have ignored its own brand value, resulting in the lack of local brand building. First, the lack of the core values of the brand. The core values of the brand is closely related to the personality of it products. Only long-term attention and promotion can ensure long-lasting influence of its core values. For example, the Hailer Company's core values are "faith", the brand slogan is "sincere forever", its products and star service are interpretation and extension of this idea. Many companies ignore the maintenance of the core values of the brand; it is difficult for some enterprises to form a sustainable development of the brand due to their ignorance of brand core values. Secondly, ignoring the personality, and the one-sided emphasis on advertising. As market competition intensifies and product selection becomes more and more diverse, advertising plays an important role in promoting selling. But advertising, after all, is the external form of packaging; the personality and quality of its products are the core strategy of brand management. Finally, the brand positioning is not accurate. In order to enter the international market, Chinese enterprises' important step is to play the price card; low price does cause concerns of consumers over a period of time, but with the international transfer of the labor market, the labor price advantage is not prominent, so the positioning of cheap price is no longer appropriate.

\section{B. Inadequate researches and cultivating of consumer brand loyalty}

According to a research on 22 brand' consumers in the United States, the average brand "(their overall characteristics) of high, medium and low degree of behavioral loyalty were $12 \%, 14 \%, 74 \%$; the height behavior brand loyalists' purchasing accounts for $69 \%$ of the sales of the brand; the low behavioral loyalty purchases only5\%, which is sufficient to illustrate the importance of a high degree of behavioral loyalty for the brand. [1]And traditional Chinese enterprises are more concerned about the production and reproduction, and only concerned about consumer repeated purchasing rate. There are no deep-seated researches about consumer psychology mechanism, and brand loyalty. Brand loyalty not exists in isolation; on the contrary, it is closely linked with the corporate brand culture, such as brand image, brand personality, brand performance. Guan Hui, and Dongtai Hai (2008) explore the impact of brand image on consumer behavior mechanism, and find that brand performance, brand personality has a direct impact on brand loyalty; fundamental way to improve customer loyalty is the development of a unique brand image, establishing a differentiated brand image, from the three dimensions of perceived quality, customer satisfaction and brand loyalty [2] Therefore, more researches on consumer loyalty are imperative.

\section{The well-known foreign brands create a strong competitive pressure on domestic commodity, and the building of domestic brand loyalty is relatively weak}

The opening up of the Chinese economy promote the well-known foreign brands to pour into the domestic market, thanks to the construction of brand loyalty they have a large number of consumers with higher loyalty. In the United States, Coca-Cola took 200 years to build brands, European brands LV spend 300 years, and SONY from Japan after World War II began construction [3]. However, China's enterprises, brand loyalty building are usually short-term behavior. For example, they regard advertising as an important means, ignore construction of brand personality; and brand operations are ineffective, put emphasis on product sales, after-sales service or continuing visiting customers are lack. At the same time, in the face of competing with many foreign well-known brands, many companies increase ads spending, apply low-cost marketing means, so it is difficult to determine the dominance of Chinese brands.

\section{STRATIGIES OF CULTIVATING CUSTOMER BRAND LOYALTY}

Based on the theory about building brand loyalty of Harris and Goode (2004): cognitive loyalty, affective loyalty, conative loyalty and behavioral loyalty, this paper forms some strategies to enhance Chinese consumers' brand loyalty.

\section{A. Put Emphasis on brand building, and guide consumers' cognitive loyalty.}

Special environment of multiple choice and online shopping makes the brand fully in front of consumers; brand building is very important to cognitive loyalty of consumers. First, establish a database of consumers in order to understand the consumer's cognitive status quo. Consumer demand are the main factors of whether brand image can be recognized, and their cognitive status are of important reference value to brand building, such as consumers' basic information, repeated purchasing rate, brand conversion rates, brand awareness, lifestyle, brand imagination, etc.. Second, collect the information of consumers' exchanging brand information. Product selection is extremely full, which prompts consumers' confusion in choosing, and shopper's evaluation becomes one of the most important criteria in purchasing some product. Therefore, Chinese brand should put emphasis on consumers' cognitive, and display the personality of their products from various views. Finally, form waning mechanism for cognitive loyalty crisis. Cognitive loyalty is divided into positive and negative cognitive loyalty. As far as the negative cognitive loyalty is formed, it will do harm to the brand' image construction. Therefore, enterprises should establish cognitive loyalty crisis early warning mechanism, and formed the ability of controlling the overall situation. 
B. Enhance the development of brand personality, promote the emotional loyalty of consumers

The emotional needs of consumers are rich and dynamic, so enterprises should base on its own power to enhance brand personality. For example, Procter \& Gamble, from Rejoice, Pantene, Safeguard, Olay, Pampers to Crest, Tide, Nanfu, almost makes out a new product in a few years, covering the main categories of daily necessities. Chinese brand personality development, first of all, should insist on the primacy of the product quality. Especially in recent years, the events of Chinese products do harm to consumers allow consumers to form cognitive bias, lack of trust on the domestic product. Only by focusing on the quality of the brand, consumers will really get emotional loyalty. At the same time, in view of the different domestic regional characteristics and cultural characteristics, domestic products should focus on its regional personality. The domestic consumer market has a strong regional personality, and consumers are on the whole more rational. These objective backgrounds need explore brand personality. Li Ning, founded in 1980, its slogan is "everything is possible". Based on the strategy of developing high-tech basketball shoes, LiNing does a deep research on the products' personality. It sponsors 3 to 3 basketball match, innovate basketball game system, which firmly seize the attention of the student population; it also signs some agreements with a number of foreign Basketball Association to broaden the brand impact on the international market, so that consumers deepen their trust and brand loyalty.

\section{Brand cultural interpretation and the formation of the consumer conative loyalty}

The conative loyalty refers to due to a deeper emotion with a certain brand, consumers have a tendency to buy the brand. [4] Zhao Guo-Jie and Yu Xiaochuan hold the view that Coca-Cola slogan for the Chinese consumer market is "3A": available, affordable and acceptable. [5] The connection of the brand personality and daily life is conative loyalty. First of all, the brand culture is the external reflection of the brand personality. Brand culture exhibition allows consumers to generate feelings of dependence and spiritual sustenance, and thus demonstrate the desire and motivation to continue to buy the goods. Second, the brand culture highlights the symbolic meaning of the brand. Sufficient goods market makes consumers have many choices. From concerning about the use value and value to the attention of the exchange value, brand culture can better demonstrate its symbolism, thereby gain consumers' accept. Finally, the accept of brands in a certain community is a powerful platform to obtain consumers conative loyalty. The rapid development of internet, blog, microblogging and other platforms have become the first choice for consumers to exchange brand experience. For example, Taobao provide the buyer with after-sales evaluation, including message and pictures of the goods, so that consumers can obtain new concessions. .

\section{Cultivate brand competitiveness, and guide consumers' loyal behavior}

An important prerequisite of behavioral loyalty is the consumers' brand accept, which depends on the level of brand competitiveness. The brand competitiveness is not only the display of product quality but also its personality compared with other similar products. JDB herbal tea originally aimed at the consumer market regions such as Guangdong, Zhejiang, with brand's aim: "preventing anger”, that is, Chinese medicine belief: preventing the fever in the body resulted from the yin and yang imbalance. It highlights the brand identity. Especially after the donation in 2008 Wenchuan earthquake, it won the recognition of consumers, making "Wanglaoji" swept the whole country. After the lawsuit, it was later changed to" JDB ", but its loyal customers still exist. So, corporate brand should base on its own strength to position its target and cultivate its competitiveness. First, the functional position allows consumers to clearly know the use value of the product; and then followed by overall positioning of the price and quality. After the in-depth analysis of consumers' demand and the market situation, the price is formed; third service positioning. Consumers' behavioral loyalty is based on quality of service.

\section{ACKNOWLEDGMENT}

The authors got found from Sichuan Provincial Department of Education issues (number: 12SB149); China West Normal University (number: 12A011).

\section{REFERENCES}

[1] Jijian and Chen xiaoping, "Emotional Model of brand loyalty behavior," Foreign Economics and Management, January , 1999,,pp.28.

[2] Guan hui and Dong dahai, Local Chinese brand on perceived quality customer satisfaction - the brand loyalty influence mechanism empirical research - based on the consumer perspective, Journal of Management, vol. 5. July, 2008, pp.587-589.

[3] Liye and Gao yurong, "Problems and countermeasures in the process of internationalization of Chinese brands," The Jiangsu providers theory, May, 2002, pp.41.

[4] Liu Li.etc, "Domestic consumer brand loyalty dimensions researchn," Statistics and Decision, April ,2008,pp.172.

[5] Zhao guojie and Yu xiaochuan, "Marketing strategy and innovation of the Coca-Cola Company in China , " Quality Spring and Autumn, September,2009.pp.24-25. 